and vigilance and standardized for American children, is evaluated for use among Swedish children. (El-Sayed E, van't Hooft I, Fried I et al. Acta Paediatr Nov 1999;88:1262-1268). Statistically significant differences are found between ADHD children and age-matched control children.

\title{
TRIAL OF CHOLINERGIC AGONIST IN ADULTS WITH ADHD
}

A novel cholinergic activating agent, ABT-418, was used to treat 29 adults with ADHD, in a double-blind, placebo-controlled, randomized, crossover trial at the Pediatric Psychopharmacology Clinic, Massachusetts General Hospital, Boston. A significantly higher proportion of patients was benefited by ABT-418 in a transdermal patch (75 mg/day) compared to placebo (40\% versus $13 \%$ ). ADHD symptom checklist scores were also significantly reduced (28\% versus $15 \%)$. Attentiveness scores and patients with less severe ADHD responded most frequently. Dizziness, skin irritation, nausea, and headaches were the most common adverse effects, and necessitated dose reduction in 6 patients and withdrawal in 1. (Wilens TE, Biederman J, Spencer TJ et al. A pilot controlled clinical trial of ABT-418, a cholinergic agonist, in the treatment of adults with attention deficit hyperactivity disorder. Am I Psychiatry Dec 1999;156:1931-1937). (Respond: Dr Wilens, Pediatric Psychopharmacology Clinic, ACC 725, Massachusetts General Hospital, Boston, MA 02114).

COMMENT. ABT-418, a nicotinic analog, may be a useful new agent in the treatment of ADHD, and especially in patients with the inattentiveness subtype (ADD) and those with less severe symptoms. The results of this trial provide further evidence of a link between nicotinic-cholinergic agents, catecholamine function, and improvement in ADHD.

EEG operant conditioning (neurotherapy) to treat ADHD is reviewed by Nash JK (Clin Electroencephalogr January 2000;31:30-37). Studies suggest that clinical improvement in ADHD is related to measurable improvements in the EEG, with a decline in theta/beta ratios over the frontal/central cortex and/or reduced theta/alpha band amplitudes.

\section{SEIZURE DISORDERS}

\section{KETOGENIC DIET IN TREATMENT OF EPILEPTIC APHASIA}

Three children, ages 9, 12 and 14 years, with acquired epileptic aphasia refractory to treatment with antiepileptic drugs, ACTH and prednisone, responded to the ketogenic diet for 12 to 26 months, in a trial at the Children's Hospital of Philadelphia, and University of Pennsylvania School of Medicine, PA. Improvements in language, and lessening of seizures and EEG seizure discharges occurred in all patients. Social interactions and behavior also improved significantly. (Bergqvist AGC, Chee CM, Lutchka LM, Brooks-Kayal AR. Treatment of acquired epileptic aphasia with the ketogenic diet. I Child Neurol Nov 1999;14:696-701). (Respond: Dr AG Christina Bergqvist, Division of Neurology, The Children's Hospital of Philadelphia, Wood Building 6th Floor, 34th and Ciovic Center Blvd, Philadelphia, PA 19104).

COMMENT. The ketogenic diet is presented as a new therapeutic alternative for patients with Landau-Kleffner syndrome. The results are promising and the method deserves further study in this frequently resistant epileptic disorder. 